NASA/TM-2013-217730

\title{
Aeromechanics Analysis of a Boundary Layer Ingesting Fan
}

Milind A. Bakhle

Glenn Research Center, Cleveland, Ohio

T.S.R. Reddy

University of Toledo, Toledo, Ohio

Gregory P. Herrick

Glenn Research Center, Cleveland, Ohio

Aamir Shabbir and Razvan V. Florea

United Technologies Research Center, East Hartford, Connecticut 


\section{NASA STI Program . . . in Profile}

Since its founding, NASA has been dedicated to the advancement of aeronautics and space science. The NASA Scientific and Technical Information (STI) program plays a key part in helping NASA maintain this important role.

The NASA STI Program operates under the auspices of the Agency Chief Information Officer. It collects, organizes, provides for archiving, and disseminates NASA's STI. The NASA STI program provides access to the NASA Aeronautics and Space Database and its public interface, the NASA Technical Reports Server, thus providing one of the largest collections of aeronautical and space science STI in the world. Results are published in both non-NASA channels and by NASA in the NASA STI Report Series, which includes the following report types:

- TECHNICAL PUBLICATION. Reports of completed research or a major significant phase of research that present the results of NASA programs and include extensive data or theoretical analysis. Includes compilations of significant scientific and technical data and information deemed to be of continuing reference value. NASA counterpart of peer-reviewed formal professional papers but has less stringent limitations on manuscript length and extent of graphic presentations.

- TECHNICAL MEMORANDUM. Scientific and technical findings that are preliminary or of specialized interest, e.g., quick release reports, working papers, and bibliographies that contain minimal annotation. Does not contain extensive analysis.

- CONTRACTOR REPORT. Scientific and technical findings by NASA-sponsored contractors and grantees.
- CONFERENCE PUBLICATION. Collected papers from scientific and technical conferences, symposia, seminars, or other meetings sponsored or cosponsored by NASA.

- SPECIAL PUBLICATION. Scientific, technical, or historical information from NASA programs, projects, and missions, often concerned with subjects having substantial public interest.

- TECHNICAL TRANSLATION. Englishlanguage translations of foreign scientific and technical material pertinent to NASA's mission.

Specialized services also include creating custom thesauri, building customized databases, organizing and publishing research results.

For more information about the NASA STI program, see the following:

- Access the NASA STI program home page at http://www.sti.nasa.gov

- E-mail your question to help@sti.nasa.gov

- Fax your question to the NASA STI Information Desk at 443-757-5803

- Phone the NASA STI Information Desk at 443-757-5802

- Write to: STI Information Desk NASA Center for AeroSpace Information 7115 Standard Drive Hanover, MD 21076-1320 
NASA/TM-2013-217730

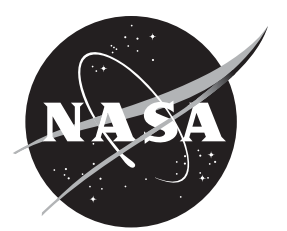

\section{Aeromechanics Analysis of a Boundary Layer Ingesting Fan}

Milind A. Bakhle

Glenn Research Center, Cleveland, Ohio

T.S.R. Reddy

University of Toledo, Toledo, Ohio

Gregory P. Herrick

Glenn Research Center, Cleveland, Ohio

Aamir Shabbir and Razvan V. Florea

United Technologies Research Center, East Hartford, Connecticut

Prepared for the

48th Joint Propulsion Conference and Exhibit

cosponsored by the AIAA, ASME, SAE, and ASEE

Atlanta, Georgia, July 30-August 1, 2012

National Aeronautics and

Space Administration

Glenn Research Center

Cleveland, Ohio 44135 


\section{Acknowledgments}

The work described in this paper was performed at NASA Glenn Research Center (GRC) in collaboration with United Technologies Research Center (UTRC). The authors would like to thank Ms. Rula Coroneos (GRC) for helping with MSC Nastran runs. The authors would like to thank Mr. David Arend (GRC Team Lead, Robust Design of Embedded Engine Systems) and Dr. Gregory Tillman (UTRC Team Lead). The authors are grateful for the support of this work provided by the Subsonic Fixed Wing Project (Dr. Rubén Del Rosario, Project Manager; Dr. Michael Hathaway, Technical Challenge Lead), and the Environmentally Responsible Aviation Project (Dr. Fayette Collier, Project Manager; Dr. Kenneth Suder, Propulsion Sub-project Manager).

Trade names and trademarks are used in this report for identification only. Their usage does not constitute an official endorsement, either expressed or implied, by the National Aeronautics and Space Administration.

This work was sponsored by the Fundamental Aeronautics Program at the NASA Glenn Research Center.

Level of Review: This material has been technically reviewed by technical management.

Available from

NASA Center for Aerospace Information 7115 Standard Drive

Hanover, MD 21076-1320
National Technical Information Service 5301 Shawnee Road Alexandria, VA 22312 


\title{
Aeromechanics Analysis of a Boundary Layer Ingesting Fan
}

\author{
Milind A. Bakhle \\ National Aeronautics and Space Administration \\ Glenn Research Center \\ Cleveland, Ohio 44135 \\ T.S.R. Reddy \\ University of Toledo \\ Toledo, Ohio 43606 \\ Gregory P. Herrick \\ National Aeronautics and Space Administration \\ Glenn Research Center \\ Cleveland, Ohio 44135 \\ Aamir Shabbir and Razvan V. Florea \\ United Technologies Research Center \\ East Hartford, Connecticut 06108
}

\begin{abstract}
Boundary layer ingesting propulsion systems have the potential to significantly reduce fuel burn but these systems must overcome the challenges related to aeromechanics - fan flutter stability and forced response dynamic stresses. High-fidelity computational analysis of the fan aeromechanics is integral to the ongoing effort to design a boundary layer ingesting inlet and fan for fabrication and wind-tunnel test. A three-dimensional, time-accurate, Reynolds-averaged Navier Stokes computational fluid dynamics code is used to study aerothermodynamic and aeromechanical behavior of the fan in response to both clean and distorted inflows. The computational aeromechanics analyses performed in this study show an intermediate design iteration of the fan to be flutter-free at the design conditions analyzed with both clean and distorted in-flows. Dynamic stresses from forced response have been calculated for the design rotational speed. Additional work is ongoing to expand the analyses to off-design conditions, and for onresonance conditions.
\end{abstract}

\section{Introduction}

Boundary layer ingestion (BLI) propulsion systems have the potential for significant reduction in aircraft fuel burn (Ref. 1); previous system studies (Refs. 2 to 6) have shown that 5 to 10 percent reduction in fuel burn is possible. Recent work (Ref. 7) has confirmed this potential benefit through a system study focused on the propulsion system and its integration into the Blended Wing Body (BWB) aircraft. The system study indicated that low-loss inlets and high-performance, distortion-tolerant turbomachinery are key technologies required to achieve a 3 to 5 percent BLI fuel burn benefit for future aircraft relative to a baseline high-performance, pylon-mounted, propulsion system. The study further identified the key sensitivity parameters and their desired targets. However, this system-level benefit could be diminished by not achieving the targets of inlet total pressure loss, fan efficiency reduction, and fan stall margin reduction. Further, the fan must meet aeromechanics requirements regarding dynamic stresses and flutter stability. Efforts (Ref. 8) are currently in progress to design and fabricate the inlet and fan for a BLI propulsion system that will be tested in a wind-tunnel to simulate cruise conditions of a representative large commercial transport aircraft. This paper describes in detail preliminary computational aeromechanics analyses performed on the boundary layer ingesting fan. The objectives of 
the aeromechanics analyses are to determine the dynamic stresses in the fan blade due to operation in a distorted inflow and to determine the flutter stability of the fan. The present aeromechanics analyses are performed at flight conditions and further studies are required at more challenging conditions including take-off.

The inlet duct that brings the flow to the fan face is a very important element of this propulsion system. Under a separate effort, the NASA Inlet A (Ref. 9) has been used as the starting point for the design of the inlet used in the current study. An optimization-based parametric inlet design system was developed and applied to considerably reduce the total pressure loss and the distortion harmonic amplitudes (Ref. 8).

\section{Fan Aerodynamic Analysis}

Fan aerodynamic analysis in the present work is based on the time-domain solution of Reynoldsaveraged Navier Stokes (RANS) equations using the TURBO aeroelastic analysis code (Refs. 10 and 11). Briefly, this is an implicit finite-volume RANS solver that uses structured multi-block grids to model flow through one or more blade rows. Previous applications of TURBO in the study of flutter and forced vibration are presented in References 12 to 14 . Further validation of TURBO in the study of aeromechanics is available in References 15 to 19. An inlet distortion boundary condition is used at the upstream boundary to prescribe the flow entering the fan domain since the inlet duct is not modeled in this part of the work. With this inlet distortion boundary condition, total conditions are held (at each respective radial and azimuthal location where prescribed) as governed by the characteristics; Herrick (Ref. 20) implemented and applied this boundary condition in previous work. A throttle exit boundary condition is used at the downstream boundary to avoid over-constraining the exit flow; this boundary condition maintains only the integrated corrected mass flow through the exit plane at a prescribed value, while local flow quantities are free to attain local equilibrium. For fan aeromechanics analysis with blade vibrations, dynamic grid deformation is used to prescribe harmonic blade vibrations and the energy method is used to evaluate aerodynamic damping and flutter stability.

Since the design of the BLI fan is in progress, the analyses presented in this paper are performed on an aerodynamic design iteration. The computational meshes used in this study of the BLI fan include a combination of $\mathrm{H}, \mathrm{O}$, and $\mathrm{C}$ block meshes. Figure 1(a) shows the computational domain for the BLI fan (one blade passage); Figure 1(b) shows the fan rotor blade and Figure 1(c) shows a cross-sectional view at a fixed radial location.

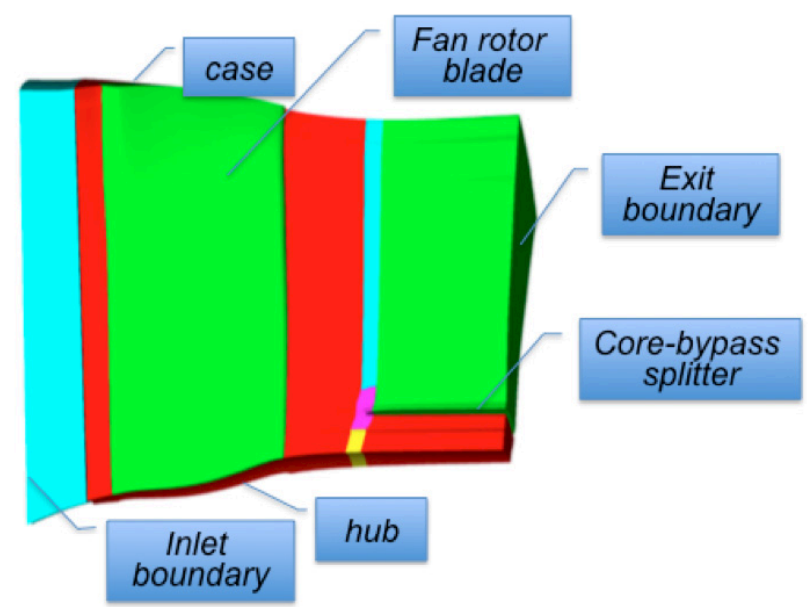

(a) Overview of computational domain (one blade passage)

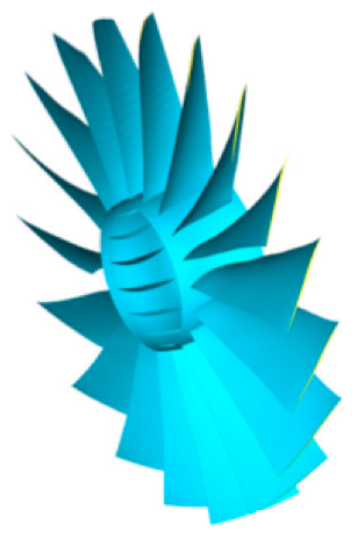

(b) Fan rotor

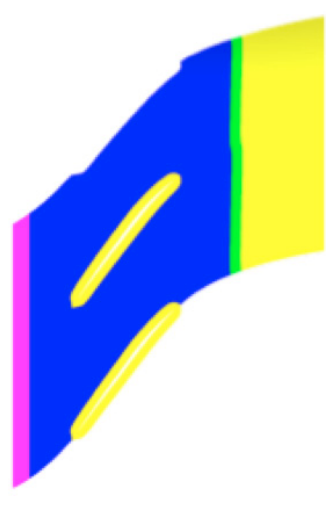

(c) Cross-sectional view

Figure 1.-Computational domain used in fan aerodynamic analysis. 


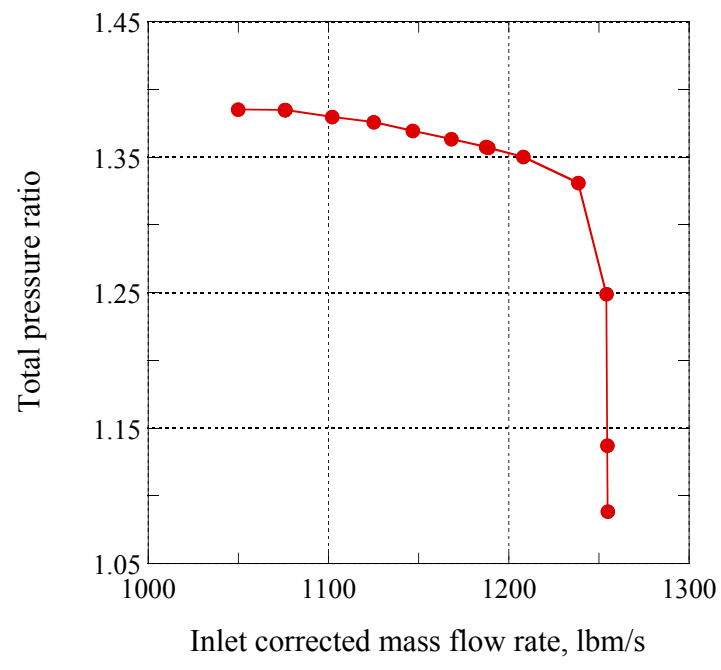

a) Total pressure ratio

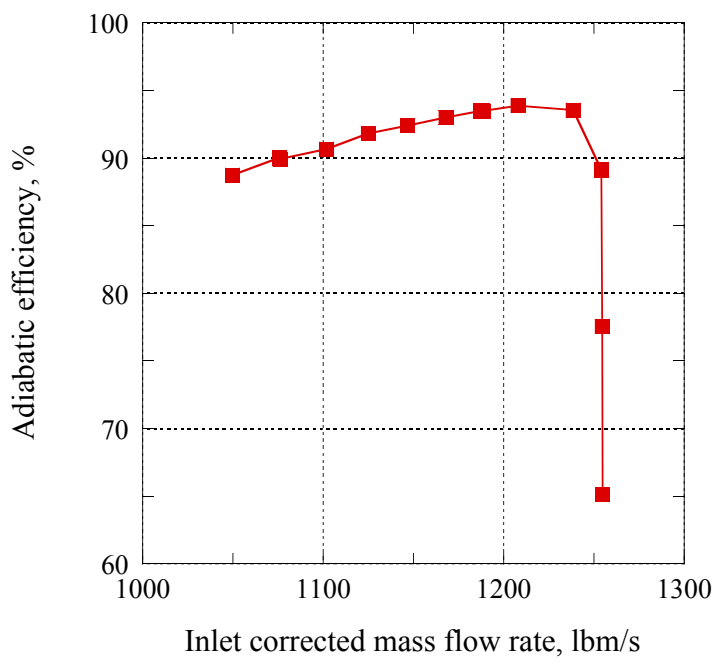

b) Adiabatic efficiency

Figure 2.-Performance characteristics of fan with clean inflow.

Initial analysis is carried out with clean inflow prescribed at the inlet boundary. This condition represents typical operation at cruise conditions for a fan operating without boundary layer ingestion. For example, an engine in a typical under-wing mount would experience clean inflow if no crosswind were present. The inlet profile has only radial variations of total pressure, total temperature, radial flow angle, and tangential flow angle. One blade passage is used for the computations and periodic boundary conditions are imposed in the circumferential direction based on an assumed symmetry of the flowfield in each blade passage. A converged solution is obtained for a prescribed exit boundary condition and the speedline is obtained by varying the exit boundary condition, keeping the rotational speed fixed. Figure 2 shows the performance characteristics of the fan, adiabatic efficiency and total pressure ratio, for the design speed. No specific attempt is made to locate the stall boundary, rather the results shown Figure 2 are those for which fully converged flowfields were obtained. The performance characteristics with clean inflow serve as a baseline for the following computations with distorted inflow.

As mentioned previously, an optimization-based parametric inlet design process (Ref. 8) was used to design the inlet with reduced inlet total pressure loss and reduced distortion harmonic amplitudes as compared to the NASA Inlet A. The inlet flowfield is not part of the current computations. Instead, the flowfield from an intermediate inlet design iteration, identified as UTRC P3 inlet in Reference 8, provides the inlet boundary condition for the fan computations. Due to the shape of the inlet, this flowfield is not axisymmetric. Rather, it contains both radial and circumferential variations in flow quantities. The relevant flow quantities required to fully prescribe the inlet boundary condition for the fan computational domain are shown in Figure 3. Note that for this computation of the 18-bladed fan, all 18 blade passages are included in the computational domain. The time-domain computations are advanced with 100 time steps per passage, or 1800 time steps per rotor revolution; the solution is converged to periodicity after 6 revolutions. Figure 4 shows the variation of the instantaneous total pressure ratio for various blade passages as these passages traverse the inlet distortion. The repeating variation for any particular passage indicates the periodicity of the flowfield in time, and the shift of the results along the time axis for different passages indicates that each passage has the same flowfield when it is at a particular circumferential location at different times. The instantaneous average value over 18 passages is also shown for comparison.

The variation of the total pressure ratio for different passages as a function of the mass flow rate through each passage is shown in Figure 5. The instantaneous average value over 18 passages is also shown for comparison. The passage mass flow rates have been multiplied by the number of passages (18) to represent values for the full rotor. The overlay of the values for two revolutions and for different passages indicates once again the periodicity in time and across the passages. The excursion of the 

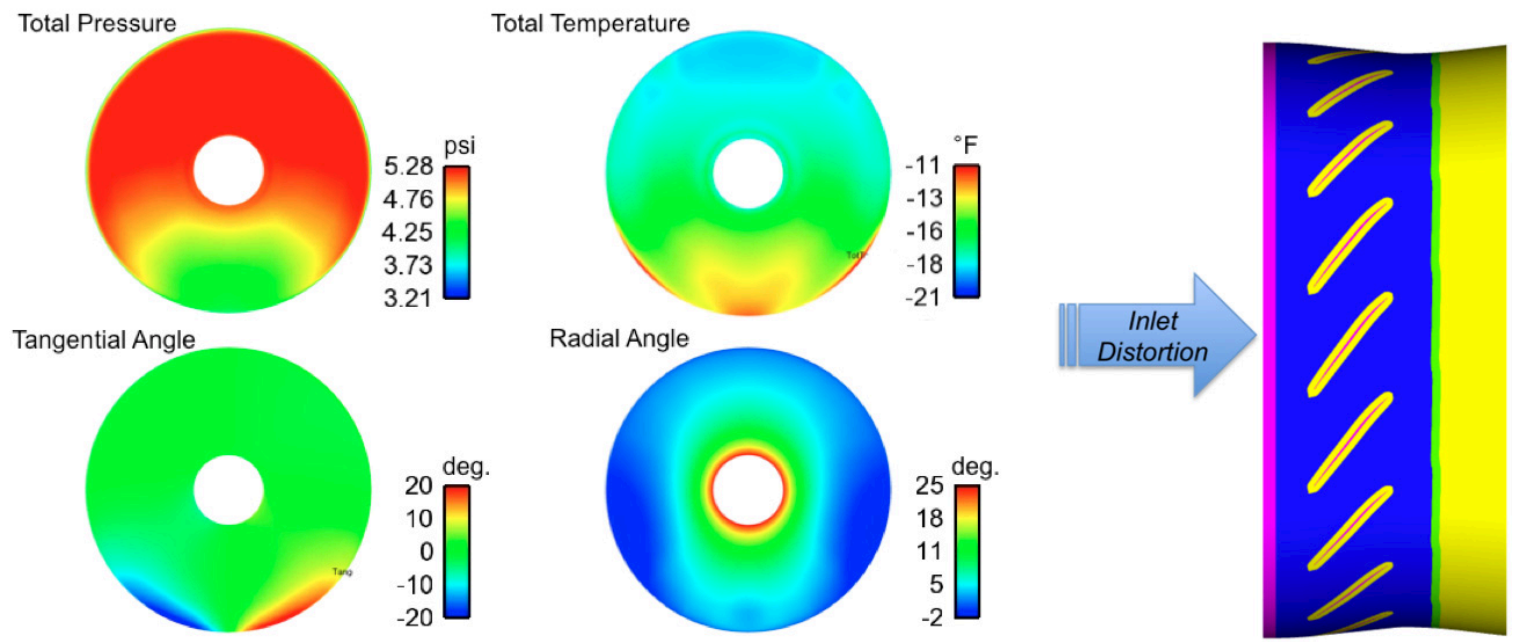

Figure 3.-Inlet boundary conditions for fan computational domain.

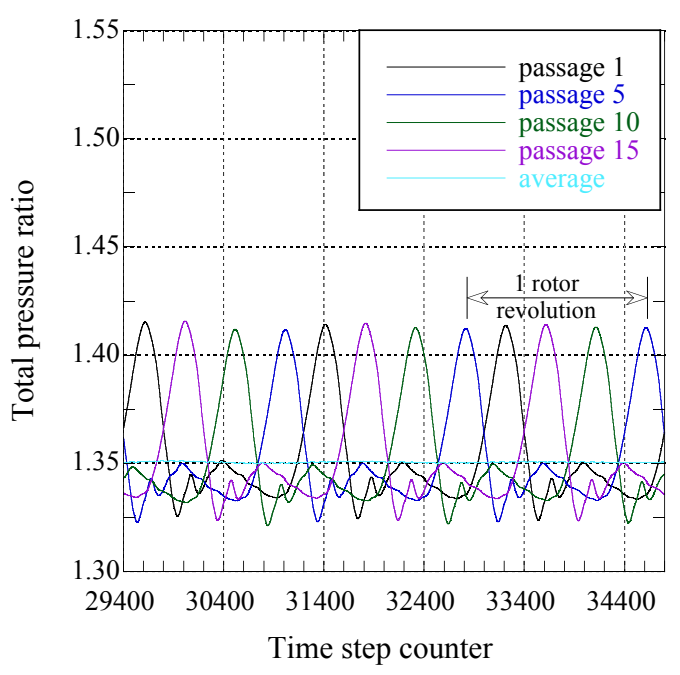

Figure 4.-Periodicity of the rotor flowfield.

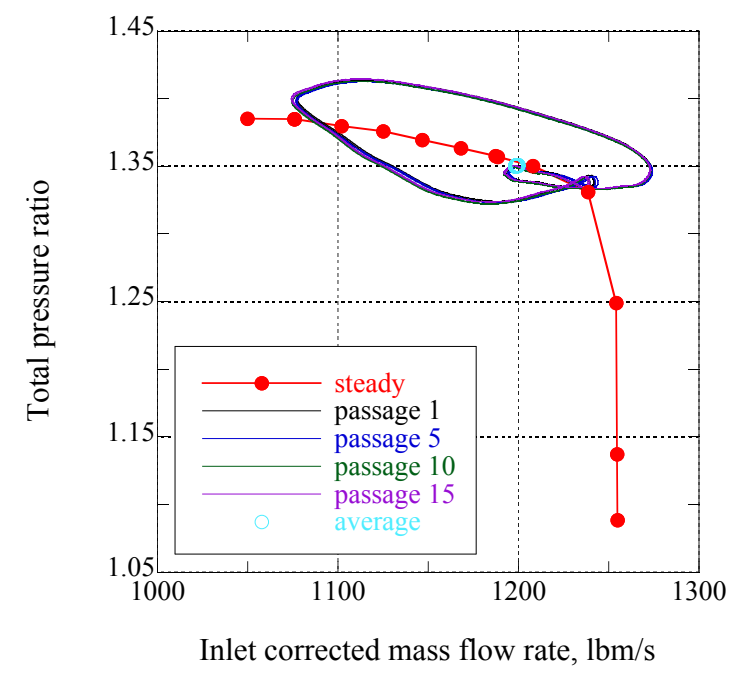

Figure 5.-Variation of performance due to inlet distortion.

instantaneous value also provides an indication of the variation in the flowfield in each passage as it traverses the inlet distortion. The nominal characteristics for clean inflow are repeated from Figure 2 for comparison. Note that a simplified approximation is used to calculate the instantaneous pressure ratio and mass flow rate in each blade passage using the grid block in place of computed stream tubes.

\section{Fan Blade Structural Analysis}

The aerodynamic design iteration of the BLI fan is used to create a structural model. It is assumed that the blades are made of Titanium alloy Ti-6Al-4V, which is typically used for scale model fan blades. In the structural model, 8-node hexahedral or brick elements are used and the blade root section is fully constrained in the analysis (no blade attachment is modeled). In addition to the centrifugal loads, nominal pressure load is prescribed. Nonlinear static and modal analyses are performed using commercial finite element analysis software to calculate the blade static deflection, static stress, and modal deflections(mode shapes), stresses, and frequencies. The analyses include the effects of centrifugal stiffening and softening. The mode shape and frequency results for the first four modes are shown in Figure 6 . It can be noted that the first mode is predominantly bending and the third mode is predominantly torsion; these two modes are considered for the flutter stability analysis in a following section. 


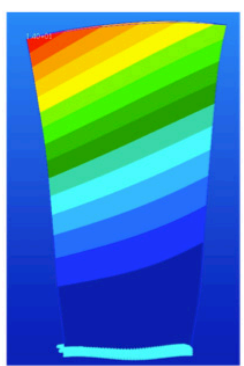

mode 1

$63.5 \mathrm{~Hz}$

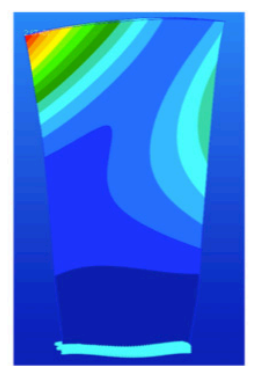

mode 2

$156.6 \mathrm{~Hz}$

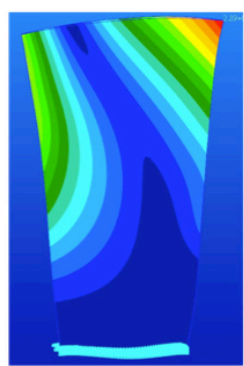

mode 3

$224.8 \mathrm{~Hz}$

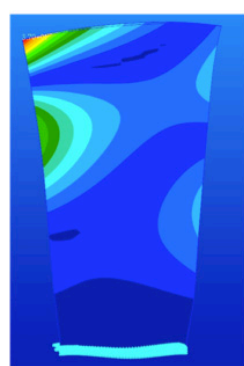

mode 4

$346.6 \mathrm{~Hz}$

Figure 6.-Fan blade vibration mode shapes and frequencies at design speed.

\section{Fan Blade Forced Vibration Response}

The blade structural dynamics can be described in modal form by the following equation:

$$
[M]\{\ddot{q}\}+[K]\{q\}=\{A D\}
$$

where $[M]$ is the modal mass matrix, $[K]$ is the modal stiffness matrix, $\{q\}$ is the generalized displacement vector, $\{A D\}$ is the motion-independent aerodynamic load vector that is referred in this context as the modal force vector, and the overdot denotes time derivative. Note that since damping is not included, this analysis is expected to provide conservative results.

For a frequency of excitation $\omega$, the generalized displacement vector of an undamped blade can be written as:

$$
\{q\}=\left[[K]-\omega^{2}[M]\right]^{-1}\{A D\}
$$

The components of modal force can be defined by the following equation:

$$
A D_{n}=\int \vec{\delta}_{n} \cdot p d \vec{A}
$$

where $\vec{\delta}$ is the modal displacement vector, $p$ is the aerodynamic pressure, $\vec{A}$ is the blade surface area vector, and the subscript $n$ denotes the mode index.

The inlet distortion provides a periodic excitation for each blade with a fundamental period of one rotor revolution. The unsteady pressure from the unsteady flowfield computed by TURBO is used with the blade modal displacement and area to calculate the modal force. Figure 7 shows this time variation of modal force for the first four modes. Since the flowfield has converged to periodicity, the modal force is seen in Figure 7 as a periodic function of time. Figure 8 shows the Fourier components of modal force. The first and second harmonics are significant in magnitude, with a rapid drop-off beyond the fourth harmonic. However, it can be noted from Equation (2) that the forced response vibration amplitude will be large if the excitation frequency is nearly equal to the natural frequency. To determine conditions at which the excitation frequency is nearly equal to the natural frequency, a Campbell diagram is constructed by repeating the modal analysis at different rotational speeds. Figure 9 shows the Campbell diagram for the fan rotor blade. The rotational speed is non-dimensionalized by the design value. The lines of constant slope are the "engine order (EO)" excitation lines that correspond to the harmonic content of the excitation. For example, the third harmonic in Figure 8 acts as a 3 EO excitation that has a frequency nearly equal to the mode 2 frequency at design rotational speed (highlighted with a circle on Figure 9). Similarly, the 7 EO excitation frequency is nearly equal to the mode 4 frequency. 
The forced vibration response or dynamic stress at design speed can be calculated to include contributions from various modes for any given engine order excitation. Rewriting Equation (2) for each harmonic (engine order), the generalized displacement for $n^{\text {th }}$ mode due to $r^{\text {th }}$ harmonic excitation can be written as:

$$
\left\{q_{n r}\right\}=\left[\left[K_{n}\right]-\omega_{r}^{2}\left[M_{n}\right]\right]^{-1}\left\{A D_{n r}\right\}
$$

Then, the blade displacements $u_{r}$ resulting from the $r^{\text {th }}$ harmonic excitation are given by:

$$
u_{r}=\sum_{n} \phi_{n} q_{n r}
$$

where $\phi_{n}$ is the $n^{\text {th }}$ mode shape. Similarly, the dynamic stress response amplitudes $\sigma_{r}$ for the $r^{\text {th }}$ harmonic excitation can be obtained from the modal stress $s_{n}$ as:

$$
\sigma_{r}=\sum_{n} s_{n} q_{n r}
$$

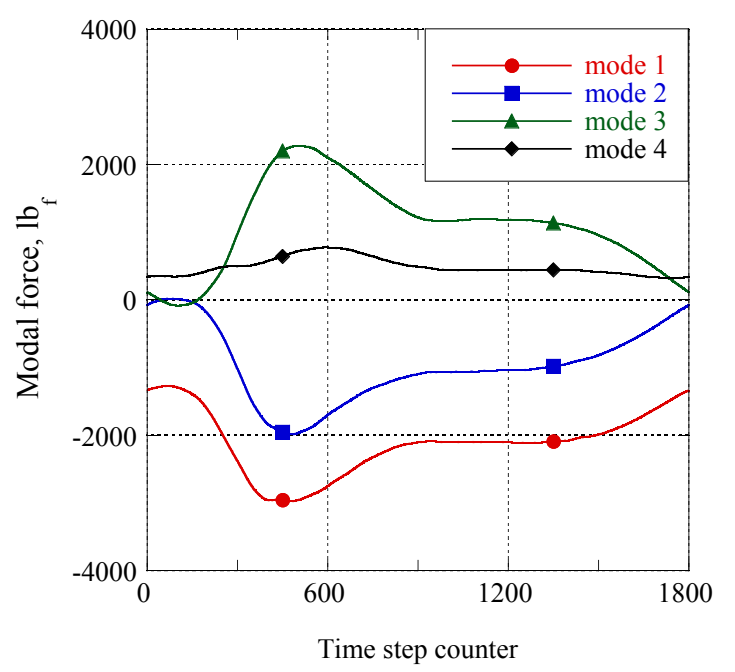

Figure 7.-Modal force variation.

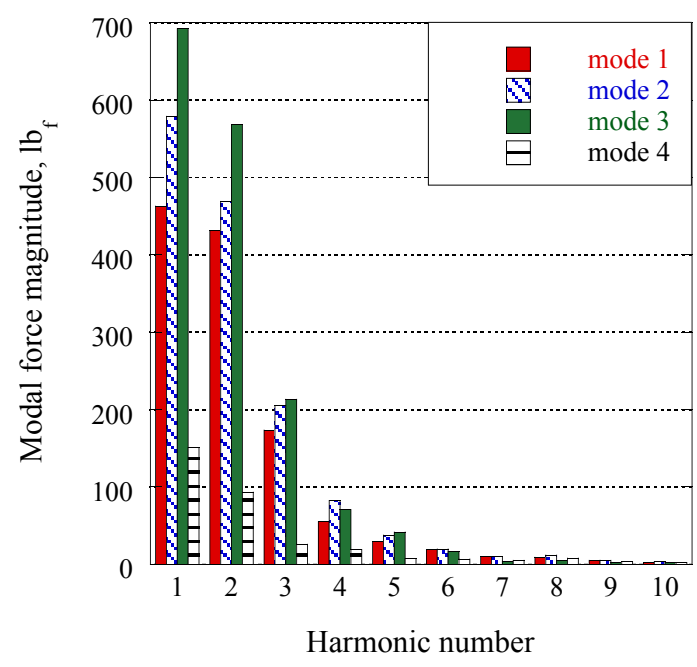

Figure 8.-Fourier components of modal force.

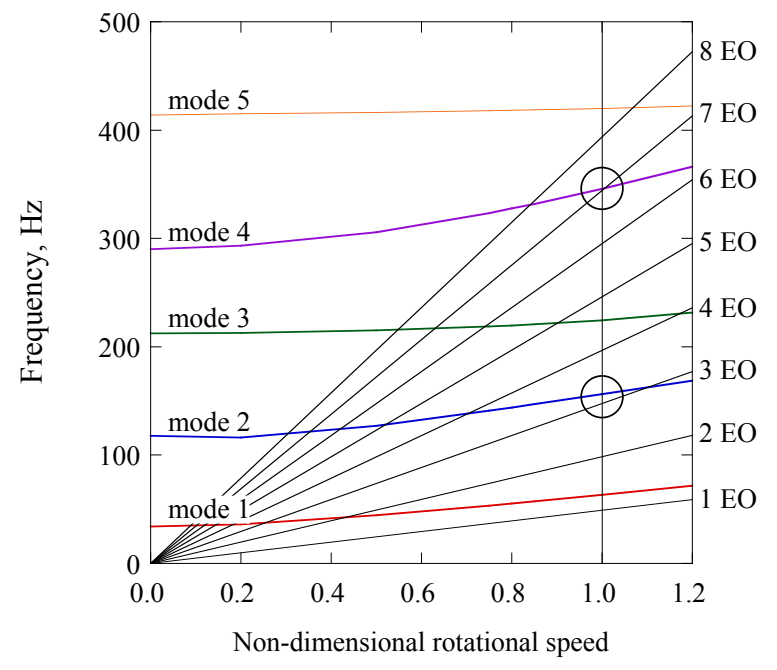

Figure 9.-Campbell diagram for BLI fan blade. 


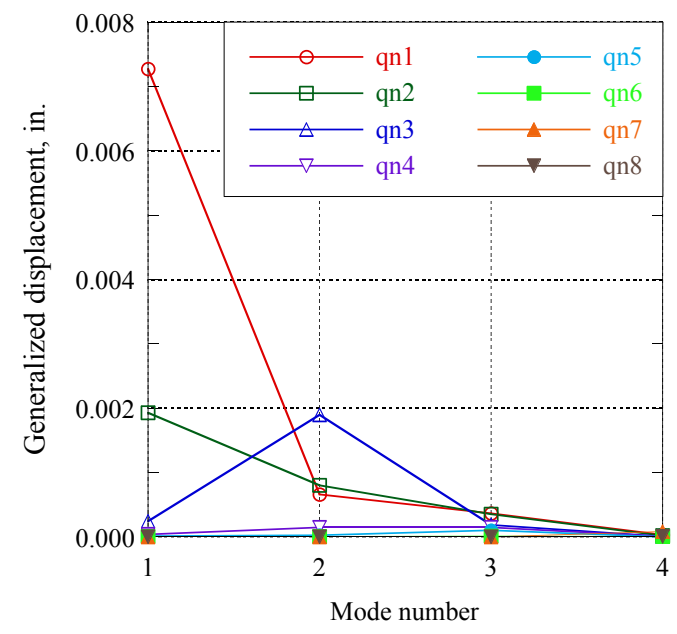

Figure 10.-Fan blade forced vibration response calculated from Equation (4).

The results of such calculations are shown in Figure 10 and Table I. Four modes are included in the analysis corresponding to eight engine order excitations. Figure 10 shows the increased generalized displacement in mode 2 for engine order 3 excitation $\left(q_{23}\right)$, resulting from an excitation frequency close to the natural frequency (as seen in Figure 9). Also, Table I shows the resulting increased dynamic stress from engine order 3 excitation. Similarly, the small frequency margin for mode 4 and engine order 7 (Figure 9) is seen to result in an increased dynamic stress from engine order 7 excitation (Table I). Note that the stress values listed in Table I are the von Mises stresses. Also, note that the analysis was done for the design rotational speed. It is expected that the on-resonance analysis near the design speed will result in significantly higher dynamic stresses. Work is in progress to perform this on-resonance analysis.

TABLE I.-VIBRATION AMPLITUDE AND DYNAMIC STRESS FOR DIFFERENT ENGINE ORDER EXCITATIONS AT DESIGN SPEED

\begin{tabular}{|c|c|c|}
\hline $\begin{array}{c}\text { Harmonic or } \\
\text { engine order }\end{array}$ & $\begin{array}{c}\text { Vibration amplitude } \\
\text { (at tip trailing edge), } \\
\text { in. }\end{array}$ & $\begin{array}{c}\text { Dynamic stress amplitude } \\
\text { (at root of blade), } \\
\text { psi }\end{array}$ \\
\hline 1 & $5.5 \times 10^{-2}$ & 273 \\
2 & $3.0 \times 10^{-2}$ & 290 \\
3 & $1.9 \times 10^{-2}$ & 666 \\
4 & $3.1 \times 10^{-3}$ & 308 \\
5 & $2.6 \times 10^{-3}$ & 169 \\
6 & $2.7 \times 10^{-4}$ & 33 \\
7 & $7.0 \times 10^{-4}$ & 427 \\
8 & $6.0 \times 10^{-5}$ & 19 \\
\hline
\end{tabular}




\section{Fan Blade Flutter Stability}

The flutter stability of the fan is evaluated using the TURBO aeroelastic analysis code. The energy method (Ref. 21) or work-per-cycle approach is used to calculate aerodynamic damping to determine flutter stability as described in Reference 22 . For a clean inflow prescribed at the inlet boundary, the flowfield through the blade row is first calculated with no prescribed blade vibration. Starting with this converged steady flowfield, blade vibrations are prescribed in a selected mode, frequency, and nodal diameter pattern or phase angle. Note that the number of different possible nodal diameter patterns is equal to the number of blades that are on the fan rotor. After the transients in the flowfield decay, and a periodic flowfield is obtained, the work done on the vibrating blade is calculated for a cycle of blade vibration as follows:

$$
W=\oint \int_{\text {surface }}-p d \vec{A} \cdot(\partial \vec{X} / \partial t) d t
$$

where, $p$ is the aerodynamic pressure due to blade vibration, $A$ is the blade surface area vector, $\vec{X}$ is the displacement vector on the blade surface, and $t$ denotes time. The aerodynamic damping ratio $(\zeta)$ can be approximately related to the work-per-cycle $(W)$ and the average kinetic energy $\left(K_{E}\right)$ of the blade over one cycle of vibration through the following expression:

$$
\zeta \approx-W / 8 \pi K_{E}
$$

If aerodynamic damping is negative, flutter can occur. Note that the structural damping (material and mechanical damping) has not been considered.

\section{Clean Inflow}

Initial fan flutter calculations are performed at design operating speed near peak efficiency condition with clean inflow prescribed at the inlet boundary. The computational domain consisted of all 18 blade passages (full rotor analysis). Figure 11 shows the results of the calculations with all blades vibrating inphase ( 0 nodal diameter) in mode 1 (bending). Individual blade values are shown to converge to the average value within 10 cycles of vibration. The converged value is positive indicating no flutter at the condition analyzed. Similar calculations are performed with vibrations in other nodal diameter patterns (different interblade phase angles). The converged results are summarized in Figure 12. It can be noted that aerodynamic damping has a fairly large range of variation with nodal diameter pattern, with low values for low nodal diameter patterns. For all nodal diameter patterns considered, aerodynamic damping is positive, indicating no flutter for the conditions analyzed, namely, design operating speed near peak efficiency condition. Since decreasing mass flow rate along the speedline (moving towards stall) can sometimes result in reduced aerodynamic damping and possibly flutter, calculations are performed at the design operating speed near stall condition (approximately 11 percent lower mass flow rate). Only results for the selected range of nodal diameter patterns are shown in

Figure 13. The lowest aerodynamic damping value is seen to decrease as the operating point is changed from near peak efficiency to near stall. For mode 1 (bending) vibrations, aerodynamic damping reaches low values for the 1 nodal diameter pattern, although all calculated values remain positive.

The results of calculations performed for mode 3 (torsion) at design operating speed near peak efficiency condition with clean inflow are shown in Figure 14. In contrast to mode 1, the aerodynamic damping stays within a narrow range of values. All calculated aerodynamic damping values are positive, indicating no flutter for the conditions analyzed; minimum values are higher for mode 3 as compared to

mode 1. Calculations are also performed at the design operating speed near stall condition for a selected 
range of nodal diameter patterns. No significant change in aerodynamic damping is observed as the operating point is changed from near peak efficiency to near stall.

\section{Distorted Inflow}

Typically, in a linear formulation, fan flutter stability and forced response due to aerodynamic excitations are considered separately. Moreover, fan inlet distortion is typically considered only in the context of cross-wind operation at low forward speed operation on the ground. In the present case of the BLI fan, the concern is that the inlet distortion is persistent at all operating conditions and includes multiple harmonics. Previous studies (Refs. 23 to 25) have indicated that nonlinear interactions between

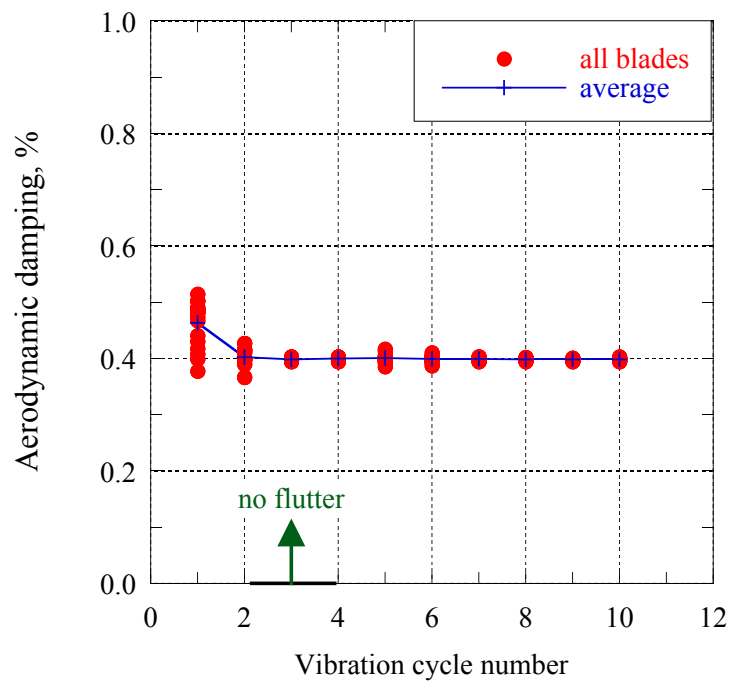

Figure 11.-Aerodynamic damping with clean inflow at design operating speed, near peak efficiency condition, mode 1 vibration, 0 nodal diameter pattern.

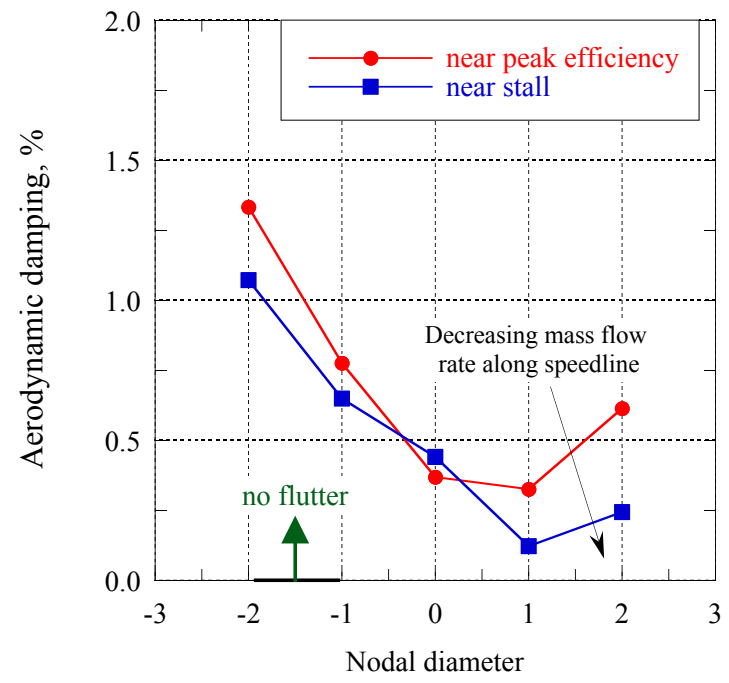

Figure 13.-Effect of operating point on aerodynamic damping with clean inflow at design operating speed, mode 1 vibration, various nodal diameter patterns.

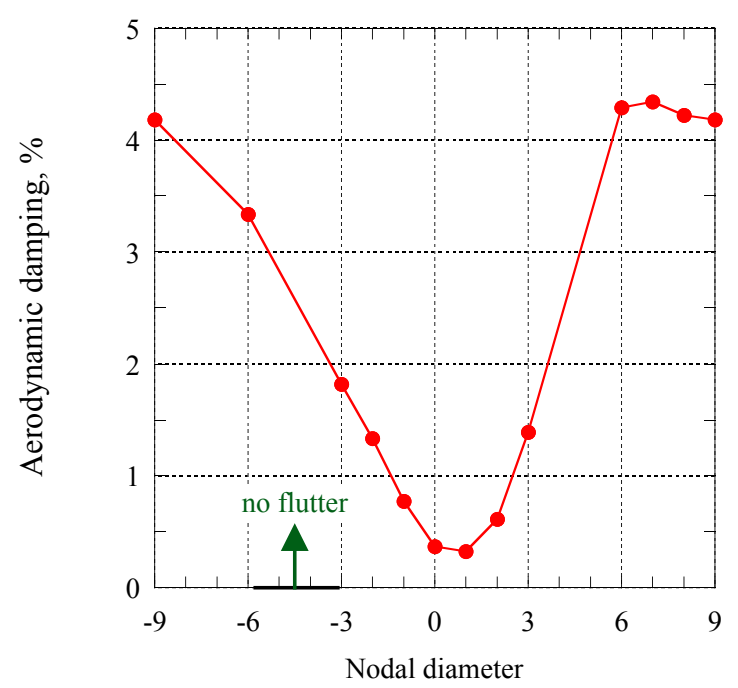

Figure 12.-Aerodynamic damping with clean inflow at design operating speed, near peak efficiency condition, mode 1 vibration, various nodal diameter patterns.

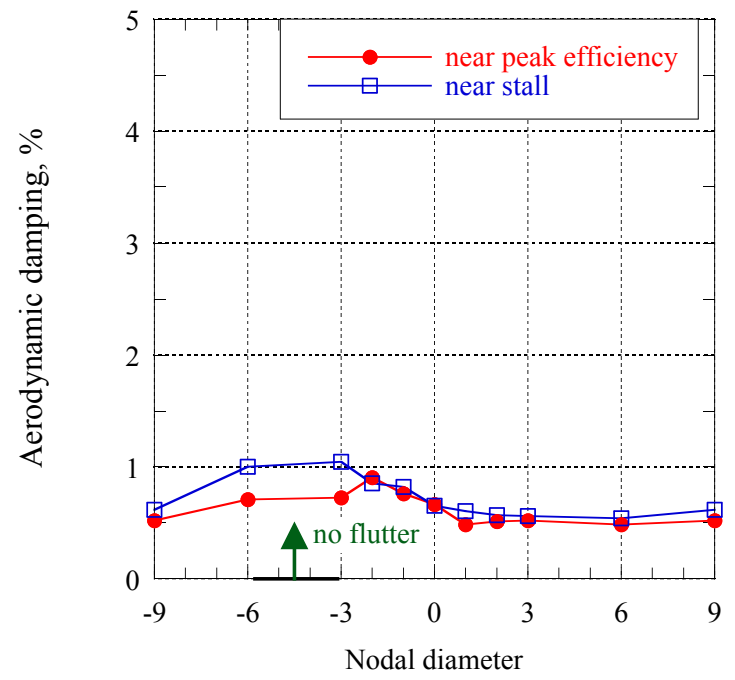

Figure 14.-Aerodynamic damping with clean inflow at design operating speed, near peak efficiency condition, mode 3 vibration, various nodal diameter patterns. 
inlet distortion and blade vibrations may be important. The influence of inlet distortion on flutter stability is related, in part, to the changes in operating conditions of individual blades as they move through the distorted inlet flow as can be seen in Figure 5. In addition, since the fan blade rotational frequency is typically not an integral multiple of the blade vibration frequency, each blade vibration cycle takes place in a different flowfield depending on the location of the blades relative to the inlet distortion.

Various approaches are considered to evaluate flutter stability with distorted inflow: (i) circumferentially average the distorted inflow to obtain an equivalent radial profile and use work-per-cycle analysis, (ii) select a portion of the inlet distortion to represent a "worst-case" inflow condition that is used at all circumferential locations and use work-per-cycle analysis, (iii) prescribe blade vibrations and distorted inflow simultaneously, use work-per-cycle analysis, average the results over all blades, and over multiple blade vibration cycles, (iv) use tightly-coupled aeroelastic analysis with distorted inflow; blade vibrations are determined as part of the computations; post-process the time history to estimate average damping over all blades and multiple vibration cycles. Upon considering the above approaches, approach (iii) is selected as the preferred approach that would avoid having to make large changes to the computational code, not be overly conservative, and not average out the effects of the inlet distortion entirely. It is recognized that due to the varying upstream conditions, each vibration cycle of each fan blade will be unique, and thus there will not be a convergence to a single value for all blades after running multiple vibration cycles. Instead, one would expect to obtain results that represent a range of aerodynamic damping values.

The calculated aerodynamic damping with distorted inflow for design operating speed, near peak efficiency condition, mode 1 vibration, and 0 nodal diameter pattern is shown in Figure 15. The results for individual blades are plotted, along with the average over all the blades. Since the period of blade vibration is not the same as the period of blade rotation, each vibration cycle for each blade occurs in a different flowfield, resulting in a different aerodynamic damping. This plot shows a variation of less than 0.3 percent in aerodynamic damping for different blades resulting from the circumferential variations in the flowfield due to the distorted inflow. The average over all blades is nearly unchanged after the first vibration cycle. Figure 16 shows the same results plotted as a variation with blade number; the average over all vibration cycles is seen to be nearly the same for all blades.

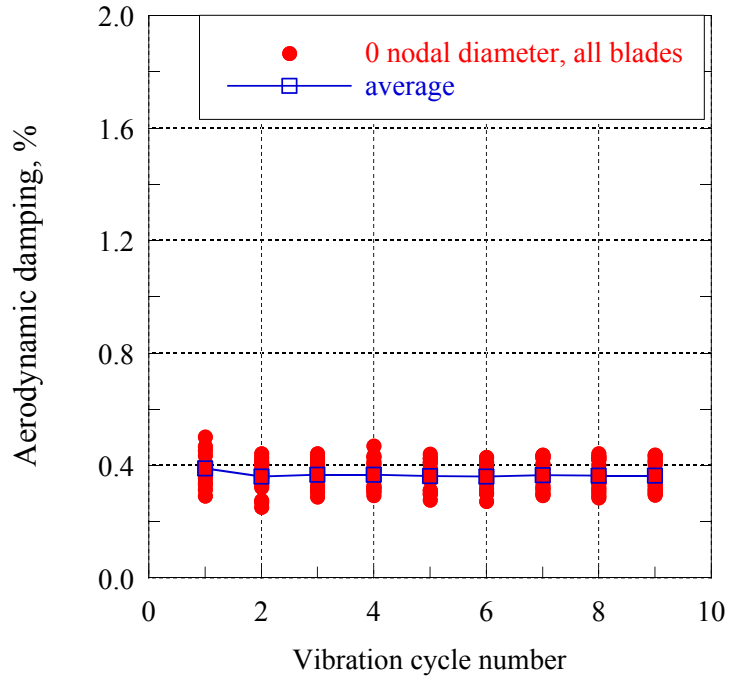

Figure 15.-Aerodynamic damping with distorted inflow at design operating speed, mode 1 vibration, 0 nodal diameter pattern.

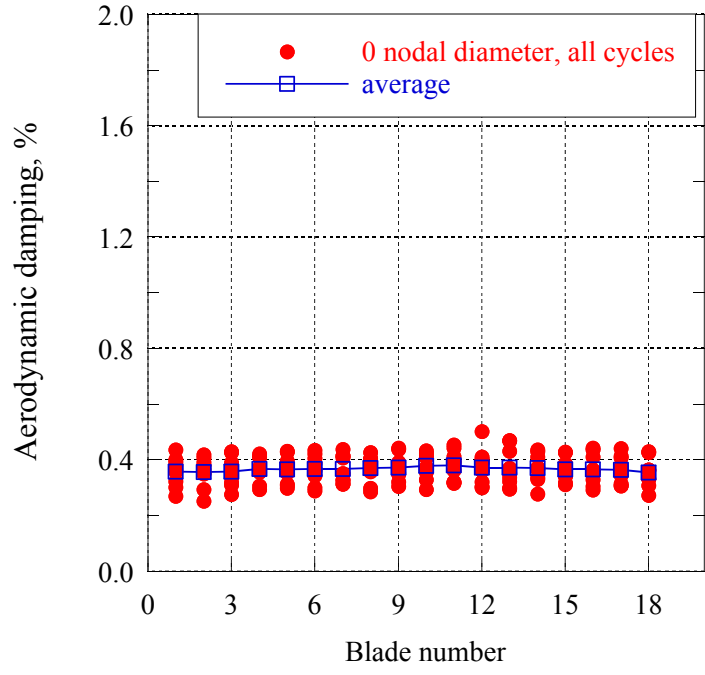

Figure 16.-Aerodynamic damping for all blades with distorted inflow at design operating speed, mode 1 vibration, 0 nodal diameter pattern. 


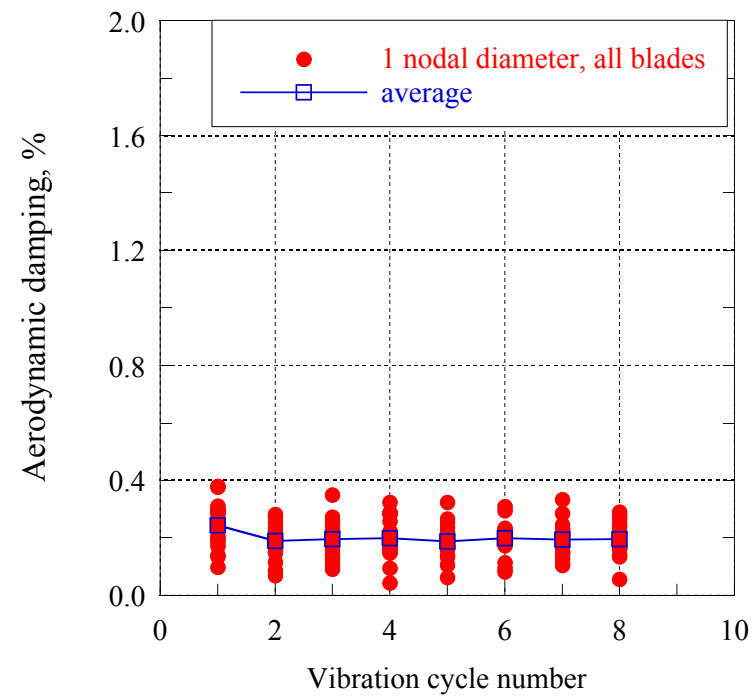

Figure 17.-Aerodynamic damping with distorted inflow at design operating speed, mode 1 vibration, 1 nodal diameter pattern.

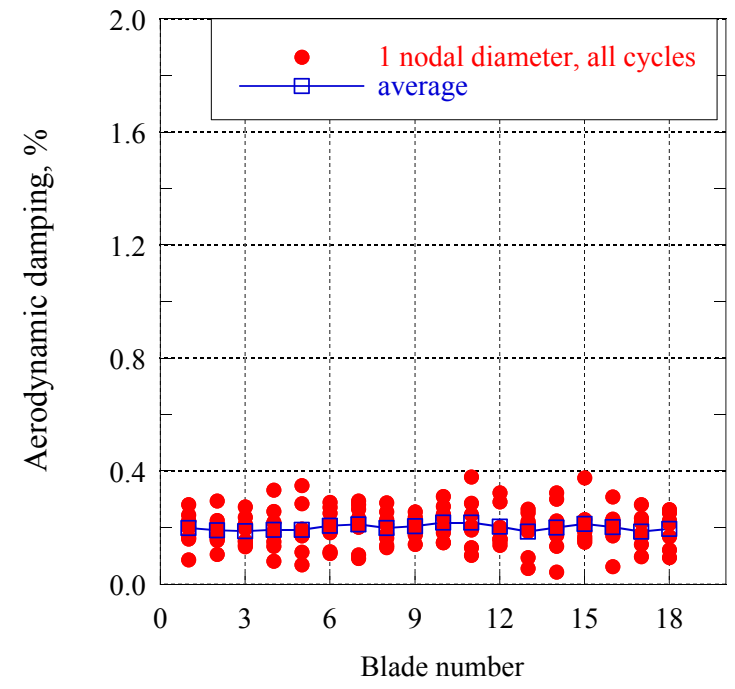

Figure 18.-Aerodynamic damping for all blades with distorted inflow at design operating speed, mode 1 vibration, 1 nodal diameter pattern.

The calculated aerodynamic damping with distorted inflow for design operating speed, near peak efficiency condition, mode 1 vibration, and 1 nodal diameter pattern is shown in Figure 17 and Figure 18. These results are of particular interest since the 1 nodal diameter pattern showed the lowest aerodynamic damping for clean inflow (Figure 13). Figure 17 shows that the range of variation in aerodynamic damping over all blades is approximately 0.3 percent, which is slightly larger than the range for 0 nodal diameter. The average value is nearly unchanged after the first vibration cycle. Figure 18 shows a slightly higher variation in average aerodynamic damping with blade number as compared to the 0 nodal diameter results (Figure 16), nonetheless this variation of the average value is quite small. As compared to the 0 nodal diameter pattern, these results show lower average values of aerodynamic damping. The differences between the average values for clean inflow and distorted inflow are quite small and all calculated values of aerodynamic damping are positive.

\section{Concluding Remarks}

To realize the benefits of Boundary Layer Ingestion (BLI) propulsion, the fan must have acceptable aeromechanical characteristics to continually operate in the persistent inlet distortion coming from the BLI inlet. In this study, an intermediate design of a fan operating with a BLI inlet has been analyzed for its aeromechanical characteristics in the presence of distorted in-flow. The inlet duct was not modeled as part of this study. Instead, the inlet distortion from a separate flow calculation was imposed as the inlet boundary condition for the fan analysis.

A structural model was created to analyze the structural dynamics characteristics of the fan, and a Campbell diagram was constructed. The forced response analysis provided the dynamic stresses at design rotational speed. Further analysis is required to examine the forced response at other rotational speeds where the engine order excitation frequency coincides with a blade natural frequency (on-resonance conditions). Further work is also needed to understand the effects of blade root fixity modeling on blade natural frequencies and mode shapes.

Baseline fan flutter analysis was performed at design speed using clean inflow conditions. The aerodynamic damping near peak efficiency condition, calculated using the energy method, was seen to have low values for low nodal diameters for the first structural mode. For operating conditions near stall, the aerodynamic damping was seen to drop to very low values. However, none of the results showed negative aerodynamic damping that would indicate flutter. Similar analysis of the third mode also showed 
no flutter at design speed, both near peak efficiency and stall conditions. Further analysis is required at off-design conditions where flutter is more frequently encountered. Also, additional analysis is required to understand the sensitivity of the flutter stability results to physical and numerical parameters.

Different approaches were considered to analyze flutter stability in the presence of the BLI distortion. Analysis was performed with both the inlet distortion and blade vibrations simultaneously modeled. No flutter was encountered in the limited number of cases examined for the first vibration mode. To reduce the possibility of aeromechanical difficulties during the operation of the BLI fan, many possible combinations of rotational speed, operating condition, vibration mode, and nodal diameter pattern need to be analyzed for flutter stability.

Current aeromechanical analyses of the intermediate design of the BLI fan have not shown any problems of flutter or forced response. The analyses completed thus far represent initial work towards risk reduction in the design and testing of the BLI fan. Future work will focus on completing the analysis for this intermediate design and performing similar analyses for the final design that will be tested in the wind tunnel. Additional follow-on work may be related to coupled inlet-fan analyses, which would model with greater accuracy the operation of this BLI fan. Further, a tightly coupled aeroelastic analysis may be considered in the future to provide more detailed and accurate representation of the interactions between blade vibrations and inlet distortion.

\section{References}

1. Smith, L. H., "Wake Ingestion Propulsion Benefit," AIAA Journal of Propulsion and Power, Vol. 9, No. 1, Jan.-Feb., 1993, pp. 74-82

2. Daggett, D., Kawai, R., and Friedman, D., "Blended Wing Body Systems Studies: Boundary Layer Ingestion Inlets with Active Flow Control," NASA/CR - 2003-212670, December 2003.

3. Kawai, R., Friedman, D., and Serrano, L., "Blended Wing Body (BWB) Boundary Layer Ingestion (BLI) Inlet Configuration and Systems Studies," NASA/CR - 2006-214534, December 2006.

4. Plas, A. P., "Performance of a Boundary Layer Ingesting (BLI) Propulsion System, AIAA-2007-450, January 2007.

5. Nickol, C. L., "Silent Aircraft Initiative Concept Risk Assessment," NASA/TM-2008-215112, February 2008.

6. Nickol, C. L., and McCullers, L. A., "Hybrid Wing Body Configuration System Studies," AIAA2009-931, January 2009.

7. Tillman, T. G., Hardin, L. W., Moffitt, B. A., Sharma, O. P., Lord, W. K., Berton, J., and Arend, D., "System-Level Benefits of Boundary Layer Ingesting Propulsion," invited presentation, AIAA 49th Aerospace Sciences Meeting, January 2011.

8. Florea, R. V., Matalanis, C., Hardin, L. W., Stucky, M., and Shabbir, A., "Parametric Analysis and Design for Embedded Engine Inlets," AIAA Paper 2012-3994, July 2012.

9. Berrier, B. L., Carter, M. B., and Allan, B. G., "High Reynolds Number Investigation of a FlushMounted, S-Duct Inlet with Large Amounts of Boundary Layer Ingestion," NASA/TP - 2005213766, 2005.

10. Chen, J.-P., and Whitfield, D. L., "Navier-Stokes Calculations for the Unsteady Flowfield of Turbomachinery,” AIAA Paper 1990-0676, January 1990.

11. Chen, J.-P. and Briley, W. R., "A Parallel Flow Solver for Unsteady Multiple Blade Row Turbomachinery Simulations,” ASME Paper GT2001-0348, June 2001.

12. Srivastava, R., Bakhle, M. A., and Keith, T. G., Jr., "Numerical Simulation of Aerodynamic Damping for Flutter Analysis of Turbomachinery Blade Rows," AIAA Journal of Propulsion and Power, Vol. 19, No. 2, March 2003.

13. Srivastava, R., Bakhle, M. A., Keith, T. G., Jr., and Stefko, G. L., "Flutter Analysis of a Transonic Fan,” ASME Paper GT-2002-30319, June 2002. 
14. Bakhle, M. A., Liu, Jong S., Panovsky, Josef, Keith, Theo G. Jr., and Mehmed, Oral, "Calculation and Correlation of the Unsteady Flowfield in a High Pressure Turbine," ASME Paper GT-200230322, June 2002.

15. Panovsky, Josef, James, Darrell K., and Hassan, Khaled K., "An Assessment of Fan Flutter Using TURBO," $5^{\text {th }}$ National Turbine Engine High Cycle Fatigue Conference, published by Universal Technology Corporation, Dayton, Ohio, April 2000.

16. Panovsky, J., Liu, J. S. and Bakhle, M. A., "Comparisons of Experimental and Computational Forced Response in a High Pressure Turbine," Proceedings of the 7th National Turbine High Cycle Fatigue Conference, published by Universal Technology Corporation, Dayton, Ohio, April 2002.

17. Kielb, Robert E., Barter, John W., Thomas, Jeffrey P., and Hall, Kenneth C., "Blade Excitation by Aerodynamic Instabilities," ASME Paper GT2003-38634, June 2003.

18. Sanders, A. J., Hassan, K. K. and Rabe, D. C., "Experimental and Numerical Study of Stall Flutter in a Transonic Low-Aspect Ratio Fan Blisk," ASME Journal of Turbomachinery, Vol. 126, No. 1, pp. 166-174, January 2004.

19. Sanders, A. J., "Stall Flutter Assessment of and Advanced Design Transonic Fan Using TURBOAE," Proceedings of the 6th National Turbine High Cycle Fatigue Conference, published by Universal Technology Corporation, Dayton, Ohio, April 2001.

20. Herrick, G. P., "Effects of Inlet Distortion on Aeromechanical Stability of a Forward-Swept HighSpeed Fan," AIAA Paper 2010-6711, August 2010.

21. Carta, F. O., "Coupled Blade-Disk-Shroud Flutter Instabilities in Turbojet Engine Rotors," Trans ASME Journal of Engineering for Power, Vol. 89, No.3, pp. 419- 426, July 1967.

22. Bakhle, M. A., Reddy, T. S. R., and Stefko, G. L., "Comparisons of Flutter Analyses for an Experimental Fan," NASA/TM-2010-216221, April 2010.

23. Li, H. D., and He, L., "Single-Passage Analysis of Unsteady Flows Around Vibrating Blades of a Transonic Fan Under Inlet Distortion," ASME Journal of Turbomachinery, Vol. 124, No. 2, pp. 285292, April 2002.

24. Ekici, K., and Hall, K. C., "Nonlinear Frequency-Domain Analysis of Unsteady Flows in Turbomachinery with Multiple Excitation Frequencies," AIAA Journal, Vol. 46, No. 8, pp. 19121920, August 2008.

25. Vahdati, M., Sayma, A. I., Bréard, C., and Imregun, M., "Computational study of intake duct effects on fan flutter stability," AIAA Journal, Vol. 40, No. 3, pp. 408-418, March 2002. 


\begin{tabular}{|c|c|c|}
\hline \multicolumn{2}{|c|}{ REPORT DOCUMENTATION PAGE } & $\begin{array}{l}\text { Form Approved } \\
\text { OMB No. 0704-0188 }\end{array}$ \\
\hline \multicolumn{3}{|c|}{$\begin{array}{l}\text { The public reporting burden for this collection of information is estimated to average } 1 \text { hour per response, including the time for reviewing instructions, searching existing data sources, gathering and maintaining the } \\
\text { data needed, and completing and reviewing the collection of information. Send comments regarding this burden estimate or any other aspect of this collection of information, including suggestions for reducing this } \\
\text { burden, to Department of Defense, Washington Headquarters Services, Directorate for Information Operations and Reports (0704-0188), } 1215 \text { Jefferson Davis Highway, Suite } 1204 \text {, Allington, VA } 22222-24302 \text {. } \\
\text { Respondents should be aware that notwithstanding any other provision of law, no person shall be subject to any penalty for failing to comply with a collection of information if it does not display a currently valid OMB } \\
\text { control number. } \\
\text { PLEASE DO NOT RETURN YOUR FORM TO THE ABOVE ADDRESS. }\end{array}$} \\
\hline $\begin{array}{l}\text { 1. REPORT DATE (DD-MM-YYYY) } \\
01-01-2013\end{array}$ & $\begin{array}{l}\text { 2. REPORT TYPE } \\
\text { Technical Memorandum }\end{array}$ & 3. DATES COVERED (From - To) \\
\hline \multirow{3}{*}{\multicolumn{2}{|c|}{$\begin{array}{l}\text { 4. TITLE AND SUBTITLE } \\
\text { Aeromechanics Analysis of a Boundary Layer Ingesting Fan }\end{array}$}} & 5a. CONTRACT NUMBER \\
\hline & & 5b. GRANT NUMBER \\
\hline & & 5c. PROGRAM ELEMENT NUMBER \\
\hline \multirow{3}{*}{\multicolumn{2}{|c|}{$\begin{array}{l}\text { 6. AUTHOR(S) } \\
\text { Bakhle, Milind, A.; Reddy, T., S., R.; Herrick, Gregory, P.; Shabbir, Aamir; Florea, Razvan, } \\
\text { V. }\end{array}$}} & 5d. PROJECT NUMBER \\
\hline & & 5e. TASK NUMBER \\
\hline & & $\begin{array}{l}\text { 5f. WORK UNIT NUMBER } \\
\text { WBS 561581.02.08.03.47.03.01 }\end{array}$ \\
\hline \multicolumn{2}{|c|}{$\begin{array}{l}\text { 7. PERFORMING ORGANIZATION NAME(S) AND ADDRESS(ES) } \\
\text { National Aeronautics and Space Administration } \\
\text { John H. Glenn Research Center at Lewis Field } \\
\text { Cleveland, Ohio 44135-3191 }\end{array}$} & $\begin{array}{l}\text { 8. PERFORMING ORGANIZATION } \\
\text { REPORT NUMBER } \\
\text { E-18442 }\end{array}$ \\
\hline \multirow{2}{*}{\multicolumn{2}{|c|}{$\begin{array}{l}\text { 9. SPONSORING/MONITORING AGENCY NAME(S) AND ADDRESS(ES) } \\
\text { National Aeronautics and Space Administration } \\
\text { Washington, DC 20546-0001 }\end{array}$}} & $\begin{array}{l}\text { 10. SPONSORING/MONITOR'S } \\
\text { ACRONYM(S) } \\
\text { NASA }\end{array}$ \\
\hline & & $\begin{array}{l}\text { 11. SPONSORING/MONITORING } \\
\text { REPORT NUMBER } \\
\text { NASA/TM-2013-217730 }\end{array}$ \\
\hline \multicolumn{3}{|c|}{$\begin{array}{l}\text { 12. DISTRIBUTIONIAVAILABILITY STATEMENT } \\
\text { Unclassified-Unlimited } \\
\text { Subject Categories: } 07 \text { and } 05 \\
\text { Available electronically at http://Www.sti.nasa.gov } \\
\text { This publication is available from the NASA Center for AeroSpace Information, 443-757-5802 }\end{array}$} \\
\hline
\end{tabular}

\section{SUPPLEMENTARY NOTES}

\section{ABSTRACT}

Boundary layer ingesting propulsion systems have the potential to significantly reduce fuel burn but these systems must overcome the challenges related to aeromechanics-fan flutter stability and forced response dynamic stresses. High-fidelity computational analysis of the fan aeromechanics is integral to the ongoing effort to design a boundary layer ingesting inlet and fan for fabrication and wind-tunnel test. A three-dimensional, time-accurate, Reynolds-averaged Navier Stokes computational fluid dynamics code is used to study aerothermodynamic and aeromechanical behavior of the fan in response to both clean and distorted inflows. The computational aeromechanics analyses performed in this study show an intermediate design iteration of the fan to be flutter-free at the design conditions analyzed with both clean and distorted in-flows. Dynamic stresses from forced response have been calculated for the design rotational speed. Additional work is ongoing to expand the analyses to off-design conditions, and for on-resonance conditions.

\section{SUBJECT TERMS}

Aeroelasticity; Inlet distortion; Flutter; Unsteady flow; Forced response; Navier-Stokes equation; Turbomachinery

\begin{tabular}{|c|c|c|c|c|}
\hline \multicolumn{3}{|c|}{ 16. SECURITY CLASSIFICATION OF: } & \multirow{2}{*}{$\begin{array}{l}\text { 17. LIMITATION OF } \\
\text { ABSTRACT } \\
\text { UU }\end{array}$} & \multirow{2}{*}{$\begin{array}{l}\text { 18. NUMBER } \\
\text { OF } \\
\text { PAGES } \\
20\end{array}$} \\
\hline $\begin{array}{l}\text { a. REPORT } \\
\mathrm{U}\end{array}$ & $\begin{array}{l}\text { b. ABSTRACT } \\
\mathrm{U}\end{array}$ & $\begin{array}{l}\text { c. THIS } \\
\text { PAGE } \\
\text { U }\end{array}$ & & \\
\hline
\end{tabular}



